\title{
Band-by-band contributions to the longwave cloud radiative feedbacks
}

\author{
Xianglei Huang ${ }^{1 *}$, Xiuhong Chen $^{1}$, Qing Yue ${ }^{2}$
}

1. Department of Climate and Space Sciences and Engineering, the University of Michigan, Ann Arbor, Michigan

2. Jet Propulsion Laboratory, California Institute of Technology, Pasadena, California

* Corresponding author: Dr. Xianglei Huang, Department of Climate and Space Sciences and Engineering, 2455 Hayward St., the University of Michigan, Ann Arbor, MI 48109-2143. xianglei@umich.edu, +1-(734)-9360491.

Key Points:

1. The band-by-band decomposition of cloud radiative feedback is studied for the first time.

2. Two different methods can give similar longwave broadband radiative feedbacks, but their band-by-band decompositions are different.

3. Seemingly agreeable broadband cloud radiative feedbacks can have different spectral decompositions, which can be related to cloud changes.

Submitted to Geophysical Research Letters on July 16, 2018

First Revision on April 22, 2019

Second Revision on May 28, 2019

This is the author manuscript accepted for publication and has undergone full peer review but has not been through the copyediting, typesetting, pagination and proofreading process, which may lead to differences between this version and the Version of Record. Please cite this article as doi: 10.1029/2019GL083466

This article is protected by copyright. All rights reserved. 


\section{Abstract}

Cloud radiative feedback is central to our projection of future climate change. It can be estimated using the cloud radiative kernel (CRK) method or adjustment method. This study, for the first time, examines the contributions of each spectral band to the longwave (LW) cloud radiative feedbacks (CRFs). Simulations of three warming scenarios are analyzed, including $+2 \mathrm{~K}$ SST, $2 \times \mathrm{CO}_{2}$, and $4 \times \mathrm{XO}_{2}$ experiments. While the $\mathrm{LW}$ broadband CRFs derived from the CRK and adjustment methods agree with each other, they disagree on the relative contributions from the far-IR and window bands. The CRK method provides a consistent band-by-band decomposition of LW CRF for different warming scenarios. The simulated and observed shortterm broadband CRFs for the 2003-2013 period are similar to the long-term counterparts, but their band-by-band decompositions are different, which can be further related to the cloud fraction changes in respective simulations and observation.

Plain Language Summary: we studied how the cloud change in response to surface temperature change leads to the changes of radiation at the top of the atmosphere (referred to as cloud radiative feedback) over different frequency ranges in the longwave (referred to as spectral bands). While different methods can provide a similar estimate of broadband cloud radiative feedbacks, the decomposition to different longwave spectral bands can be different from one method to another. The cloud radiative kernel method can provide a more consistent band-by-band decomposition of the longwave cloud radiative feedback for different warming

This article is protected by copyright. All rights reserved. 
scenarios. The decomposition for cloud radiative feedback derived from the warming experiments is considerably different from that derived from decadal-scale observations and simulations. Such differences in spectral band decomposition can be related to the specific cloud fraction changes for different types of clouds defined with respect to cloud top pressure and cloud opacity.

This article is protected by copyright. All rights reserved. 


\section{Introduction}

Cloud radiative feedback (CRF) refers to the change of top-of-atmosphere (TOA) radiative flux caused by the responses of clouds to a secular change of global surface temperature. It plays a critical role in our understandings of future climate changes in response to the increase of greenhouse gases (Boucher et al., 2013 and references there-in). There has been a large spread in terms of the CRFs simulated by different climate models (Flato et al., 2013 and references there-in; Caldwell et al. 2016; Vial et al., 2013). How to use observations to test such simulated CRFs remains a challenging yet meaningful question with immediate implications (Klein and Hall, 2015), especially given the fact that we have accumulated more than a decade of coordinated satellite observations for cloud fields and other ancillary variables from NASA A-Train observations (Stephens et al., 2002; Stephens et al., 2018).

Initially, the change of cloud radiative effect due to surface warming is used to study CRFs. But later it was realized that the change of cloud radiative effect includes the change of clear-sky radiative flux caused by other radiative feedbacks (Soden et al. 2004). Adjustment method was then used to estimate CRFs, which takes the differences between all-sky and clearsky radiative feedbacks as well as the radiative forcings into account (Soden et al., 2008; Shell et al. 2008). Zelinka et al. (2012) developed a radiative kernel technique to estimate cloud radiative feedback and has been widely used since then (e.g. Zelinka et al. 2013; Zhou et al. 2013; Ceppi et al. 2016; Caldwell et al. 2016; Sedlar \& Tjernström 2017). The radiative kernel technique computes the radiative flux Jacobian with respect to cloud fraction in 2-dimensional

This article is protected by copyright. All rights reserved. 
diagram defined by cloud top pressure (CTP) and cloud visible optical depth $\left(\tau_{\text {vis }}\right)$, thus circumventing the issue of an ill-defined Jacobian with respect to cloud fraction in 3dimensional geometric space.

Aforementioned CRF studies focus on longwave or shortwave broadband flux changes, which are the summation of changes over individual spectral channels. An issue with the broadband flux diagnostics is that, due to compensating differences from each spectral band, a model can have a seemingly good agreement with the observation (or another model) on the broadband diagnostics but for the wrong reasons. For example, Huang et al. (2008) showed how the GFDL AM2 model agrees with observations for the clear-sky broadband greenhouse efficiency, but such agreement arises from compensating errors originated from the $\mathrm{H}_{2} \mathrm{O}$ band and the mid-IR window band. Another example highlighting this issue was given in Huang et al. (2014b), which examined spectral details of longwave radiative feedbacks and showed that two GCMs can have identical broadband lapse-rate feedbacks but significantly different spectral decompositions. Spectral fluxes and cloud radiative effects can be derived from NASA A-Train observations without implicit retrievals of geophysical variables (Huang et al. 2008; Huang et al. 2010; Chen et al. 2013b; and Huang et al. 2014a). They can also be directly output from climate models at the bandwidths used in their radiation schemes. While the rich information in the longwave spectral decomposition of climate radiative feedbacks and cloud radiative effects (CREs) have been studied before, the spectral LW CRF has never been explored before. These

This article is protected by copyright. All rights reserved. 
facts motivated this study with two objectives. First, the band-by-band contribution to the longwave (LW) CRF will be documented for both model simulations and observational analysis. Second, this study will further relate such band-by-band diagnostics of CRF with cloud fraction changes seen in the model and observations. The numerical experiments and the methods to derive band-by-band cloud radiative kernels (CRKs) are described in Section 2. The spectral decompositions of CRFs for different simulations and observations, as well as the connections to cloud fraction change, are discussed in Section 3. Summaries and further discussions are then given in Section 4.

\section{Models and Methodology}

\subsection{Model and simulation set-up}

This study employed the Community Earth System Model (CESM) version 1.1.1. Details about the CESM can be found in Gent et al. (2011). The atmosphere model of it, CAM4 (Community Atmospheric Model, version 4), has a horizontal resolution of $1.9^{\circ}$ latitude by $2.5^{\circ}$ longitude and 26 layers in the vertical. Its radiation scheme, RRTMG (Mlawer et al., 1997; Clough et al., 2005), has sixteen bands from $10 \mathrm{~cm}^{-1}$ to $3250 \mathrm{~cm}^{-1}$ for the longwave. Slab-ocean version of the CESM model was used to carry out three numerical experiments, for current $\mathrm{CO}_{2}$ concentration, $2 \times \mathrm{CO}_{2}$, and $4 \times \mathrm{CO}_{2}$, respectively. Each experiment was run for 20 years and the last ten years of output were used in the analysis. In addition, the CAM4 model was used to carry out two simulations: one forced by the observed SST from 2000 to 2013, and the other

This article is protected by copyright. All rights reserved. 
forced by uniform $2 \mathrm{~K} \mathrm{SST}$ increase of the observed SST over the same period (termed as $+2 \mathrm{~K}$ SST run). The output from 2003 to 2013 were used for a short-term CRF analysis, which is to be compared with the short-term CRF derived from the A-Train observations.

\subsection{Derivation of cloud radiative kernel from the CESM simulations}

For each aforementioned CESM simulation, we use the 3-hourly output to derive CRK in a way similar to the observation-based CRK derived in Yue et al. (2016). For each spatial grid and each calendar month, the CRKs are calculated as the monthly-mean TOA (top of atmosphere) cloud radiative effect (CRE) divided by monthly-mean cloud fraction $(C)$ for each cloud type defined onto the ISCCP $7 \times 7$ joint CTP $-\tau_{\text {vis }}$ diagram (Rossow and Schiffer, 1999),

$$
C R K_{i, j, m}\left(x, y ; \Delta v_{n}\right)=\frac{\overline{C R E_{i, j}\left(x, y, t ; \Delta v_{n}\right)}}{\overline{C_{i, j}(x, y, t)}}
$$

where $i$ and $j$ denote discrete interval for CTP and $\tau_{\text {vis, }}$ respectively, $m$ denotes a given calendar month, and $\Delta v_{n}$ denotes the $\mathrm{n}$-th spectral band in the RRTMG_LW scheme. Overbar denotes a monthly average of all 3-hourly data for a given grid centered at latitude $y$, longitude $x$, CTP and $\tau_{\text {vis. }}$ TOA CRE is defined as the difference between all-sky and clear-sky TOA fluxes (both fluxes defined downward positive). Note that the CESM can be configured to output the TOA flux for each individual spectral band used in the RRTMG_LW. Unlike Yue et al. (2016) in which the synergy of the TOA CRE, cloud fraction, CTP and $\tau_{\text {vis }}$ was obtained from a variety of pixel-scale collocated observations, here all relevant variables are from the same set of instantaneous CESM output. The CTP and $\tau_{\text {vis }}$ used to classify cloud types are not direct CESM outputs. Instead,

This article is protected by copyright. All rights reserved. 
they were computed using the 3-hourly model output in a way similar to that used in the satellite simulator package COSP (Bodas-Salcedo et al., 2011). Details of the derivations were described in the supporting information. Note that CTP here is the infrared effective cloud top pressure, which is directly related to TOA LW radiation budget and the band-by-band decomposition of the cloud radiative feedbacks (Huang et al., 2014). Using the 3-hourly mean CTP and $\tau_{\text {vis, }}$ for every spatial grid, we categorize the 3-hourly cloud fraction and TOA CRE (for both broadband and spectral band) onto the CTP- $\tau_{\text {vis }}$ diagram. The monthly-mean cloud fraction and TOA CRE for a given bin $(\mathrm{i}, \mathrm{j})$ on the CTP- $\tau_{\text {vis }}$ diagram can then be computed, and the broadband and band-by-band CRKs can be derived using Eq. (1) and 10 years of 3-hourly simulation output.

Such derivations of CRKs do not need off-line radiative transfer calculations and, indeed, utilize the statistics from the GCM simulation itself. The methodology can be used to derive the CRK for each climate model tailored to its own cloud simulation statistics and cloud-radiation parameterizations. Top panels in Figure 1 show January global-mean LW broadband CRK from Zelinka et al. (2012), from Yue et al. (2016), and as derived in this study. The CRK derived in this study resembles the one from Zelinka et al. (2012) to a large extent. All three CRKs show the largest Jacobian for high and optically thick clouds. The most noticeable differences between the observation-based CRK and the two model-based CRKs are for optically thin middle and low clouds, the categories for which satellite retrievals usually are not as reliable as for optically 
thick clouds. The observation-based spectral LW CRK for the RRTMG_LW spectral bands is shown in Figure 1d, which is based on Yue et al. (2016) and utilized the spectral fluxes derived from collocated AIRS and CERES observations (Huang et al., 2008; Huang et al., 2010; Chen et al., 2013b; Huang et al., 2014a). The CESM-based CRK for each RRTMG_LW band is shown in Figure 1e. The $630-700 \mathrm{~cm}^{-1}$ band is at the center of $\mathrm{CO}_{2} v_{2}$ band and sensitive to absorptions and emissions in the stratosphere; this is why its Jacobian with respect to cloud fraction change in the troposphere is essentially zero. Except for $630-700 \mathrm{~cm}^{-1}$ band, the CRKs of other bands exhibit similar features as the broadband CRK with the largest Jacobian for each band being seen for the optically thick high cloud bins. The absolute values of CRK are small for the bands > $1390 \mathrm{~cm}^{-1}$ because the absolute TOA flux in such bands is indeed small. The largest CRKs are seen in the $820-980 \mathrm{~cm}^{-1}$ band, an RRTMG_LW band in the window region. For high clouds, the CRKs in the rest window bands and in two far-IR bands $\left(350-500\right.$ and $\left.500-630 \mathrm{~cm}^{-1}\right)$ are comparable to each other. For middle and low clouds, the CRKs in the far-IR bands are smaller than those in the window bands. This contrast is due to the fact that the far-IR band is featured with strong absorptions and emissions from upper tropospheric humidity (UTH) while the window band has little absorptions and emission from the upper troposphere. Thus, due to the masking effect of UTH in the far-IR, changes in low and middle clouds affect the far-IR TOA flux less than that window-band TOA flux. Meanwhile, changes in the high clouds can be equally seen from the far-IR and window bands, as shown in Figure $1 \mathrm{~d}$ and $1 \mathrm{f}$ and elaborated in a

This article is protected by copyright. All rights reserved. 
previous study on the band-by-band CRE (Huang et al., 2010). Later this far-IR vs. window band contrast will be used to help interpret a contrast between the long-term and short-term CRFs. The CRKs for other calendar months exhibit the same features as described above (e.g., the CRKs for July are shown in Figure S1 in the supporting information).

\subsection{Adjustment method}

The adjustment method was introduced in Soden et al. (2008) as a way to estimate CRF from the change of cloud radiative effect (dCRE). The two quantities, for the LW, are related as

$$
C R F=\left[d C R E+\left(K_{T}^{0}-K_{T}\right) d T+\left(K_{q}^{0}-K_{q}\right) d q+\left(G^{0}-G\right)\right] / d T s
$$

where $\mathrm{K}^{0} \mathrm{~S}$ are the clear-sky radiative kernels and $\mathrm{G}^{0}$ is clear-sky radiative forcing, and $\mathrm{K}$ and $\mathrm{G}$ are all-sky radiative kernel and radiative forcing, respectively. Subscripts $\mathrm{T}$ and $\mathrm{q}$ denote temperature (including surface temperature) and water vapor, respectively. Huang et al. (2014b) have developed and validated a set of LW spectral radiative kernels for temperature, humidity, and $\mathrm{CO}_{2}$, for both all-sky and clear-sky situations. The band-by-band cloud radiative effect can be output from the CESM simulations. Thus, Eq. (2) can then be used to compute the CRFs for LW broadband as well as for each individual RRTMG_LW band.

\section{Results}

\subsection{Comparisons of two methods}

For each numerical experiment described in Section 2.1, 3-hourly outputs were used to build the CRKs for every RRTMG_LW band. The CRFs were computed for the $2 \times \mathrm{CO}_{2}$ and $4 \times \mathrm{CO}_{2}$

This article is protected by copyright. All rights reserved. 
slab-ocean simulations with respect to the current $\mathrm{CO}_{2}$ slab-ocean simulation. They were also computed for the $+2 \mathrm{~K}$ SST run with respect to the CAM4 simulation forced by the observed SST. Both the CRK and adjustment methods are used to derive the cloud feedback for each case. Figure 2 shows the LW broadband CRFs as derived using the two methods as well as the difference between them. Two methods agree well with each other for both the global LW CRF and the spatial distribution. The difference in the LW broadband global-mean CRF between the two methods is only $-0.03 \mathrm{Wm}^{-2} / \mathrm{K}$ for the $+2 \mathrm{~K} \mathrm{SST}$ experiment, and $0.01 \mathrm{Wm}^{-2} / \mathrm{K}$ for the $2 \times \mathrm{CO}_{2}$ and $4 \times \mathrm{CO}_{2}$ experiments.

When the LW broadband CRFs are decomposed to each RRTMG_LW spectral band as shown in Figure 3, it becomes clear that such good broadband agreements between the two methods are results of compensating differences from different spectral bands. Using the kernel method, the four RRTMG_LW bands contributing the most to the LW cloud feedbacks are two far-IR bands $\left(350-500 \mathrm{~cm}^{-1}\right.$ and $\left.500-630 \mathrm{~cm}^{-1}\right)$, one band in the wing of $\mathrm{CO} 2 \mathrm{v}_{2}$ band $\left(700-820 \mathrm{~cm}^{-1}\right)$, and $820-980 \mathrm{~cm}^{-1}$ in the window region. Such partitioning features is applicable to all three experiments analyzed in Figure 3. Moreover, among the four RRTMG_LW bands, $820-980 \mathrm{~cm}^{-1}$ contributes the most for all three experiments and the far-IR band $500-630 \mathrm{~cm}^{-1}$ always comes as the second (red bars in Figure 3). Using the adjustment method, the 820-980 $\mathrm{cm}^{-1}$ window band contributes the most to the LW CRF for the $+2 \mathrm{~K}$ SST run (Figure 3a), followed by the two far-IR bands $\left(350-500 \mathrm{~cm}^{-1}\right.$ and $\left.500-630 \mathrm{~cm}^{-1}\right)$. However, the two far-IR bands

This article is protected by copyright. All rights reserved. 
become the two leading contributors for the $2 \times \mathrm{CO}_{2}$ and $4 \times \mathrm{CO}_{2}$ experiments. Moreover, the $820-980 \mathrm{~cm}^{-1}$ window band contributes little to the CRF for the $4 \times \mathrm{CO}_{2}$ run experiments and only the fifth largest contributor for the $2 \times \mathrm{CO}_{2}$ run (Figures $3 \mathrm{~b}$ and $3 \mathrm{c}$ ). Kernel results in each panel of Figure 3 were obtained using averages of two corresponding kernels (e.g., an average of two kernels from observed SST run and from +2K SST run are used to obtain kernel results in Figure 3a). If we simply used one kernel constructed from the $2 \times \mathrm{CO}_{2}$ run to analyze all three experiments, the band-by-band decomposition features described above still hold (Figure S2 in the support information).

Figure S3 and S4 in the supporting information are spatial maps of band-by-band CRFs for the $2 \times \mathrm{CO}_{2}$ run (except $630-700 \mathrm{~cm}^{-1}$ band that has no sensitivity to clouds) as derived using the adjustment method and the kernel method, respectively. For each band, the spatial map largely resembles that of LW broadband CRF (Figure 2) and major spatial features are consistent for all bands. Thus, the difference between the two methods is primarily on the amplitudes of the feedback as shown in Figure 3 rather than the spatial features of the feedback. As far as the cloud feedbacks for the $2 \times \mathrm{CO}_{2}$ and $4 \times \mathrm{CO}_{2}$ are concerned, the features of band-by-band decompositions should be largely the same unless the cloud changes to the $2 \times \mathrm{CO}_{2}$ and $4 \times \mathrm{CO}_{2}$ are considerably different from each other. The kernel method does provide consistent bandby-band decompositions of the CRFs for the two experiments, while the adjustment method show considerable differences in band-by-band decomposition for the two experiments. Note

This article is protected by copyright. All rights reserved. 
that the band-by-band decomposition from the adjustment method is largely consistent with that from the kernel method for the $+2 \mathrm{~K}$ SST experiment, but not for the $2 \times \mathrm{CO}_{2}$ and $4 \times \mathrm{CO}_{2}$ experiments. Since there is no change of radiative forcing for the $+2 \mathrm{~K}$ SST run, the term of $\left(\mathrm{G}^{0}-\mathrm{G}\right)$ in Equation2 is zero. The contrasts between the two methods shown in Figure 3, therefore, indicate that the differences between the adjustment method and the kernel method are, to a large extent, due to the uncertainties in estimating band-by-band features of all-sky and clearsky differences for other radiative feedbacks and forcings shown at the right sides of Eq. (2). The CRK method is not subject to such uncertainties. Thus, for the following analysis, we use the CRK method to obtain the band-by-band decomposition of CRFs.

\subsection{Band-by-band decomposition of short-term cloud feedbacks}

Using the spectral CRK developed by Yue et al. (2016) and cloud observations from the Aqua MODIS instrument (Yue et al. 2017), the LW band-by-band cloud feedback to the interannual climate variability then can be computed in a way similar to Zhou et al. (2013) and Dessler (2010; 2013). Short-term here refers to variations over the decade, in contrast to secular change. The simulated counterpart was derived using the CRK constructed from the CAM4 run forced by observed SST over the same period. The results are summarized in Figure 4. The broadband short-term LW cloud feedbacks from both CESM simulation and observation over the 11-year period are $0.19 \mathrm{Wm}^{-2} \mathrm{~K}^{-1}$. The spatial patterns are also similar to each other

(Figure $4 \mathrm{a}$ and $4 \mathrm{~b}$ ). The fractional contribution of each RRTMG_LW band to the broadband LW

This article is protected by copyright. All rights reserved. 
CRF is shown in Figure 4c, for both the short-term CRF and the CRF from the $+2 \mathrm{~K} \mathrm{SST,} 2 \times \mathrm{CO}_{2}$ and $4 \times \mathrm{CO}_{2}$ warming experiments. A consistent band-by-band decomposition is seen between the observed and simulated short-term feedbacks, with the largest contribution (48-49\%) from the RRTMG_LW window bands $\left(820-1180 \mathrm{~cm}^{-1}\right)$ and the entire far-IR band $\left(10-630 \mathrm{~cm}^{-1}\right)$ contributing only $\sim 25-26 \%$ (Fig. $4 \mathrm{c}$ and $4 \mathrm{~d}$ ). This is in sharp contrast to the band-by-band decomposition of the all three simulated long-term CRFs, for which the total fractional contribution from all the RRTMG_LW far-IR bands is comparable to or even larger than that from the window bands. Such a contrast can be understood in terms of vertically resolved cloud fraction changes (Fig. 4e). All the long-term runs have the largest cloud fraction response in the upper troposphere above $440 \mathrm{hPa}$, which is consistent with the findings from Zhou et al. (2015) based on the CMIP5 model ensembles. As mentioned in section2, high-cloud fraction changes likely cause comparable CRFs in both far-IR and window bands, since the masking effect of the UTH on the high-cloud CRF is limited. For the AMIP run and observations, changes of high-cloud fraction are comparable to those of low- and middle-cloud fraction, silimiar to what is reported in Zhou et al. (2013) based on MODIS observations. However, the middle- and low-cloud fraction changes lead to larger CRFs in the window band than in the far-IR, due to the masking effect of the UTH in the far-IR. As a result, a contrast in the fractional contributions to the total CRF can be seen between the long-term CRFs and the short-term CRFs as shown in Fig. 4c and 4d. The short-term (interannual) cloud feedback can have different spectral decomposition

This article is protected by copyright. All rights reserved. 
from the long-term cloud feedback, and it also further highlights the merit of using the far-IR in conjunction with the mid-IR window band to probe CRFs for both the short-term climate variability and long-term climate change, and to connect such band-by-band CRFs with cloud amount changes in the different vertical ranges through the troposphere.

\section{Conclusions and Discussions}

This study investigates the spectral dimension of the LW cloud feedback to both the interannual climate variability and long-term climate change. The CRKs, which are consistent with the climate model parameterizations, are directly built from the high-frequency output of the model simulations without using additional off-line radiative transfer calculations. Although both the CRK method and the adjustment method give consistent estimate of broadband LW CRFs, their spectral decomposition are not guaranteed to be the same. The spectral decomposition for the CRF derived from the adjustment method depends on the spectral decompositions of other LW feedbacks and $\mathrm{CO}_{2}$ forcing. The CRK method, on the other hand, is not constrained by such preconditions. Our results suggest that the CRK method is a more practical choice for estimating CRF and its band-by-band decomposition, as it can give consistent band-by-band decompositions for the CRFs derived from the $2 \times \mathrm{CO}_{2}$ and $4 \times \mathrm{CO}_{2}$ simulations. The results using the CRK method indicate that the fractional contribution of the far-IR and window bands to the LW CRF is largely consistent across different warming scenarios. The short-term cloud feedback on the interannual timescale derived from observations and the

This article is protected by copyright. All rights reserved. 
CAM simulations are similar to each other with the good agreements on both the global-mean magnitude and the spectral decomposition, although differences over the mid-latitudes and the tropical central Pacific are noticeable. However, the short-term CRF has distinctly different band-by-band decomposition from its long-term counterparts derived from the warming experiments (+2K SST, doubling and quadrupling of $\mathrm{CO}_{2}$ ), especially for the fractional contributions from the window and far-IR bands. Such contrast in the simulated long-term vs. short-term CRFs is physically consistent with the simulated different cloud fraction response to global-mean surface temperature between the long-term climate change signals and shortterm (interannual) variability. The cloud fraction responses reported here are consistent with previous numerical model studies on long-term high cloud responses (e.g. Hartmann \& Larson, 2002; Zelinka \& Hartmann, 2010), as well as observational and modeling studies on short-term cloud responses (e.g. Zhou et al., 2013; Zhou et al., 2015). We note that window band flux has been observed by CERES on Terra and Aqua for more than 15 years. Our study here implies that using such window-band flux observations in conjunction with CERES broadband flux and other A-Train cloud observations can potentially further constrain the short-term cloud feedbacks simulated by climate models, and better relate the changes of high, middle, and low cloud amounts with the band-by-band LW CRFs, providing a more complete delineation of the longwave CRFs. Our study also suggests that future methods to connect short-term and long-

This article is protected by copyright. All rights reserved. 
term LW CRFs should ensure not only a consistency in broadband but also a physically-based consistency in band-by-band decomposition.

\section{Acknowledgements}

The code for the CESM used in this study can be downloaded from https://svn-ccsmrelease.cgd.ucar.edu/model_versions/cesm1_1_1. This study is supported by NASA grants NNX16AP32G and 80NSSC18K1033 awarded to the University of Michigan. QY was supported by a NASA NNH15ZDA001N-CCST grant through the NASA CloudSat and CALIPSO Science Team Recompete program. MODIS data were obtained through the Level-1 Atmosphere Archive and Distribution System (LAADS; http://ladsweb.nascom.nasa.gov/). The kernel described in Zelinka et al. (2012) can be downloaded from https://markdzelinka.wordpress.com/kernels/. The spectral radiative kernel in Huang et al. (2014b) can be downloaded from http://wwwpersonal.umich.edu/ xianglei/SRK.html. The data used to generate the figures and tables in this study can be obtained by contacting the corresponding author.

This article is protected by copyright. All rights reserved. 


\section{References:}

Bodas-Salcedo, A., et al. (2011), COSP: Satellite simulation software for model assessment, Bull. Am. Meteorol. Soc., 92, 1023-1043.

Boucher, O. and Co-authors (2013). Clouds and Aerosols. In: Climate Change 2013: The Physical Science Basis. Contribution of Working Group I to the Fifth Assessment Report of the Intergovernmental Panel on Climate Change [Stocker, T.F., Qin, D., Plattner, G.-K., Tignor, M., Allen, S.K., Boschung, J., Nauels, A., Xia, Y., Bex, V. and Midgley, P.M. (eds.)]. Cambridge University Press, Cambridge, United Kingdom and New York, NY, USA.

Caldwell, P. M., Zelinka, M. D., Taylor, K. E., Marvel, K. (2016). Quantifying the Sources of Intermodel Spread in Equilibrium Climate Sensitivity. Journal of Climate, 29, 513-524.

Ceppi, P., M cCoy, D. T., and Hartmann, D. L. (2016). Observational evidence for a negative shortwave cloud feedback in middle to high latitudes. Geophysical Research Letters, 43, 1331-1339, doi:10.1002/2015GL06749.

Chen, X. H., Huang, X. L., and Liu, X. (2013a). Non-negligible effects of cloud vertical overlapping assumptions on longwave spectral fingerprinting studies. Journal of Geophysical Research: Atmospheres, 118, 7309-7320,doi.org/10.1002/ jgrd.50562.

Chen, X. H., Huang, X. L., Loeb, N. G., Wei, H. L. (2013b). Comparisons of clear-sky outgoing farIR flux inferred from satellite observations and computed from three most recent reanalysis products. Journal of Climate, 26(2), 478-494, doi:10.1175/JCLI-D-12-00212.1.

This article is protected by copyright. All rights reserved. 
Clough, S.A., Shephard, M.W., Mlawer, E. J., Delamere, J. S., Iacono, M. J., Cady-Pereira, K., Boukabara, S., Brown, P.D. (2005). Atmospheric radiative transfer modeling: a summary of the AER codes. Journal of Quantitative Spectroscopy and Radiative Transfer, 91, 233-244.

Dessler, A. E. (2010). A determination of the cloud feedback from climate variations over the past decade. Science, 330, 1523-1527, doi:10.1126/science.1192546.

Dessler, A. E. and Loeb, N. G. (2013). Impact of dataset choice on calculations of the short-term cloud feedback. Journal of Geophysical Research: Atmospheres,118, 2821-2826, doi:10.1002/jgrd.50199.

Ebert, E. E., and Curry, J. A. (1992). A parametrization of ice cloud optical properties for climate models, Journal of Geophysical Research: Atmospheres, 97, 3831-3836.

Flato, G. and Co-authors (2013). Evaluation of Climate Models. In: Climate Change 2013: The Physical Science Basis. Contribution of Working Group I to the Fifth Assessment Report of the Intergovernmental Panel on Climate Change [Stocker, T.F., Qin, D., Plattner, G.-K., Tignor, M., Allen, S. K., Boschung, J., Nauels, A., Xia, Y., Bex, V. and Midgley, P.M. (eds.)]. Cambridge University Press, Cambridge, United Kingdom and New York, NY, USA.

Fouquart, Y. (1987). Radiative transfer in climate models, in Physically Based Modelling and Simulation of Climate and Climate Changes, edited by M. E. Schlesinger, pp. 223-284, Kluwer Acad., Norwell, Mass.

This article is protected by copyright. All rights reserved. 
Gent, P. R., Danabasoglu, G., Donner, L. J., Holland, M. M., Hunke, E. C., Jayne, S. R., Lawrence, D. M., Neale, R. B., Rasch, P. J., Vertenstein, M., Worley, P. H., Yang, Z.-L., and Zhang, M. (2011). The Community Climate System Model Version 4. Journal of Climate, 24, 4973-4991. Hartmann, D. L., and Larson, K. (2002). An important constraint on tropical cloud-climate feedback, Geophys. Res. Lett., 29(20), 1951, doi:10.1029/2002GL015835.

Huang, X. L., Chen, X. H., Potter, G. L., Oreopoulos, L., Cole, J. N.S., Lee, D.M., Loeb, N. G. (2014a). A global climatology of outgoing longwave spectral cloud radiative effect and associated effective cloud properties. Journal of Climate, 27, 7475-7492, doi:10.1175/JCLI-D13-00663.1.

Huang, X. L., Chen, X. H., Soden, B. J., Liu, X.(2014b). The spectral dimension of longwave feedbacks in the CMIP3 and CMIP5 experiments. Geophysical Research Letters, 41, doi:10.1002/2014GL061938.

Huang, X. L., Loeb, N. G., and Yang, W. Z. (2010). Spectrally resolved fluxes derived from collocated AIRS and CERES measurements and their application in model evaluation: 2. cloudy sky and band-by-band cloud radiative forcing over the tropical oceans. Journal of Geophysical Research: Atmospheres, 115, D21101, doi:10.1029/2010JD013932, 2010.

Huang, X. L., Yang, W. Z., Loeb, N. G., and Ramaswamy, V. (2008). Spectrally resolved fluxes derived from collocated AIRS and CERES measurements and their application in model

This article is protected by copyright. All rights reserved. 
evaluation: 1. clear sky over the tropical oceans. Journal of Geophysical Research:

Atmospheres, 113, D09110, doi:10.1029/2007JD 009219, 2008.

Klein, S. and Hall, A. (2015). Emergent Constraints for Cloud Feedbacks. Current Climate Change Reports,1, 1-12.

Mlawer, E. J., Taubman, S. J., Brown, P. D., lacono, M. J. and Clough, S. A. (1997). Radiative transfer for inhomogeneous atmospheres: RRTM, a validated correlated-k model for the longwave. Journal of Geophysical Research, 102: doi: 10.1029/97JD00237.

Rossow, W. B., and Schiffer, R. A. (1999). Advances in understanding clouds from ISCCP. Bulletin of the American Meteorological Society, 80, 2261-2288, doi:10.1175/1520-0477.

Sedlar, J., and M. Tjernström (2017), Clouds, warm air, and a climate cooling signal over the summer Arctic, Geophys. Res. Lett., 44, 1095-1103, doi: 10.1002/2016GL071959.

Schwarkzopf, M. D. and Ramasamy, V. (1999), Radiative effects of $\mathrm{CH}_{4}, \mathrm{~N}_{2} \mathrm{O}$, halocarbons and the foreign - broadened $\mathrm{H}_{2} \mathrm{O}$ continuum: A GCM experiment. Journal of Geophysical Research: Atmospheres, 104, 9467-9499.

Shell, K. M., Kiehl, J. T. and Shields, C. A. (2008). Using the radiative kernel technique to calculate climate feedbacks in NCAR's community atmospheric model. Journal of Climate. 21, $2269-2282$.

Soden, B. J., Broccoli, A. J., and Hemler, R. S. (2004). On the use of cloud forcing to estimate cloud feedback. Journal of Climate, 17, 3661-3665.

This article is protected by copyright. All rights reserved. 
Soden, B. J., Held, I. M., Colman, R., Shell, K. M., Kiehl, J. T., and Shields, C. (2008). Quantifying climate feedbacks using radiative kernels. Journal of Climate. 21, 3504-3520.

Stephens, G. L., and Coauthors (2002). The CloudSat mission and the A-Train: A new dimension of space-based observations of clouds and precipitation. Bulletin of the American Meteorological Society, 83, 1771-1790, doi:10.1175/BAMS-83-12-1771.

Stephens G., and Co-authors (2018). CloudSat and CALIPSO within the A-Train: Ten Years of Actively Observing the Earth System. Bulletin of the American Meteorological Society, March 2018, 569-581, doi:10.1175/BAMS-D-16-0324.1.

Vial, J., Dufresne, J.-L., Bony, S. (2013). On the interpretation of inter-model spread in CMIP5 climate sensitivity estimates. Climate Dynamics, 41,3339-3362.

Yue, Q., Kahn, B. H., Fetzer, E. J., Schreier, M., Wong, S., Chen, X. H., Huang, X. L. (2016). Observation-based Longwave Cloud Radiative Kernels Derived from the A-Train, J. Climate, $29,2023-2040$.

Yue, Q., Kahn, B. H., Fetzer, E. J., Wong, S., Frey, R., and Meyer, K. G. (2017). On the response of MODIS cloud coverage to global mean surface air temperature. Journal of Geophysical Research: Atmospheres, 122, 966-979, doi:10.1002/2016JD025174.

Zelinka, M. D., and Hartmann, D. L. (2010). Why is longwave cloud feedback positive? J. Geophys. Res., 115, D16117, doi:10.1029/2010JD013817.

This article is protected by copyright. All rights reserved. 
Zelinka, M. D., Klein, S. A. and Hartmann, D. L. (2012). Computing and partitioning cloud feedbacks using cloud property histograms. Part I: Cloud radiative kernels. Journal of Climate, 25, 3715-3735, doi:10.1175/JCLI-D-11-00248.1.

Zelinka, M., Klein, S., Taylor, K., Andrews, T., Webb, M., Gregory, J., and Forster, P. (2013). Contributions of different cloud types to feedbacks and rapid adjustments in CMIP5. Journal of Climate, 26, 5007-5027, doi:10.1175/JCLI-D-12-00555.1.

Zhou, C., Zelinka, M. D., Dessler, A. E., and Klein, S. A. (2015). The relationship between interannual and long-term cloud feedbacks. Geophys. Res. Lett., 42, 10,463-10,469, doi:10.1002/2015GL066698.

Zhou, C., Zelinka, M. D., Dessler, A. E., and Yang, P. (2013). An analysis of the short-term cloud feedback using MODIS data. Journal of Climate, 26, 4803-4815, doi:10.1175/JCLI-D-1200547.1.

This article is protected by copyright. All rights reserved. 


\section{Figure Captions}

Figure 1. (a). The global-mean longwave (LW) cloud radiative kernel for January as computed in Zelinka et al. (2012). CTP refers to cloud top pressure and $\tau_{\text {vis }}$ refers to the visible cloud optical depth. (b) Same as (a) except based on Yue et al. (2016), which is derived from A-Train observations. (c) Same (b) except derived from the CESM simulation as described in Section 2. (d) The band-by-band decomposition of the cloud radiative kernel shown in (b). (e) The bandby-band decomposition of the cloud radiative kernel shown in (c).

Figure 2. Left column: the LW cloud feedback as derived using the adjustment method. From top to bottom are results based on $+2 \mathrm{KSST}, 2 \times \mathrm{CO}_{2}$ run, and $4 \times \mathrm{CO}_{2}$ runs, respectively. Middle column: same as the left column but derived using the cloud radiative kernel method. The kernel is derived from 3-hourly CESM simulation output using the method described in Yue et al. (2016). Right column: the difference between the middle and left column. The global-mean value is labeled on top of each panel.

Figure 3. Decomposition of global LW cloud feedback onto the RRTMG_LW bands. Black and red bars are for the adjust and cloud radiative kernel methods, respectively. (a) for the $+2 \mathrm{~K}$ SST run. (b) for the $2 \times \mathrm{CO}_{2}$ run. (c) for the $4 \times \mathrm{CO}_{2}$ run. For each panel, the kernels built from the corresponding control run and the warming scenario run are averaged and used to derive the feedback. Broadband cloud feedbacks for three runs are labeled on three panels, respectively.

This article is protected by copyright. All rights reserved. 
Figure 4. (a) The short-term cloud feedback derived from the CESM simulation forced by observed SST from 2003 to 2013. The CESM cloud radiative kernel is used. (b) Same as (a) but from the A-Train observations and the observation-based cloud radiative kernel in Yue et al. (2016) is used. (c) Fractional contribution of each RRTMG_LW band to the LW broadband cloud feedbacks. Different colors are for different simulations and observation as labeled on the plot. (d) The fractional contribution of the far-IR vs. mid-IR window region to LW cloud feedback for different simulations and observation. (e) Global-mean cloud fraction response to $1 \mathrm{~K}$ global mean surface temperature increase, for all analyses shown in (c) and (d).

This article is protected by copyright. All rights reserved. 
(a)

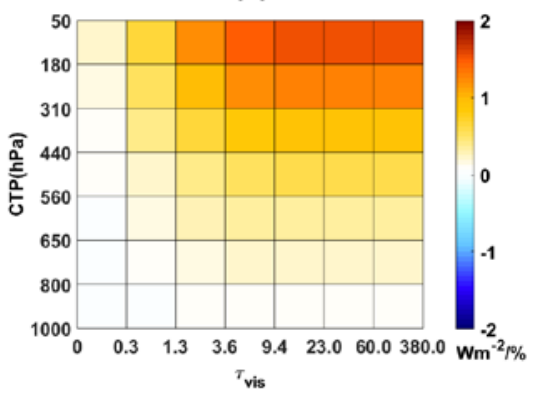

(d)

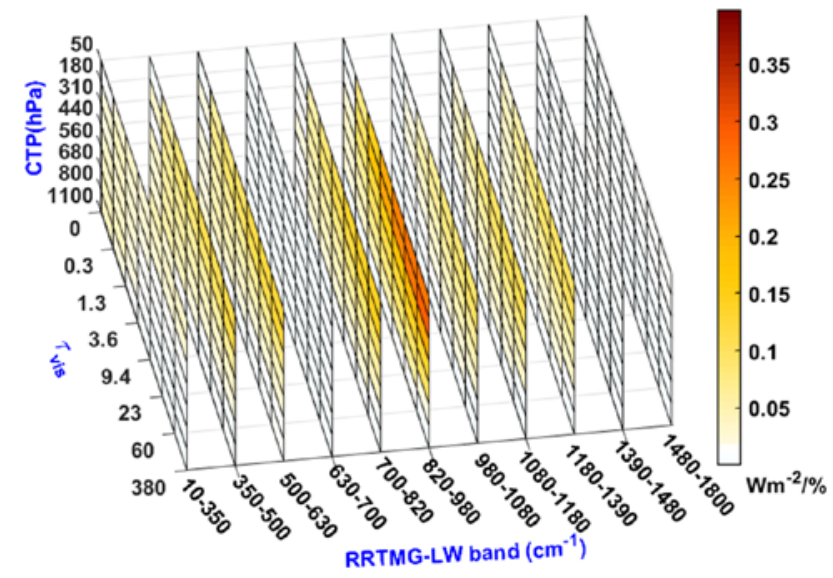

(b)
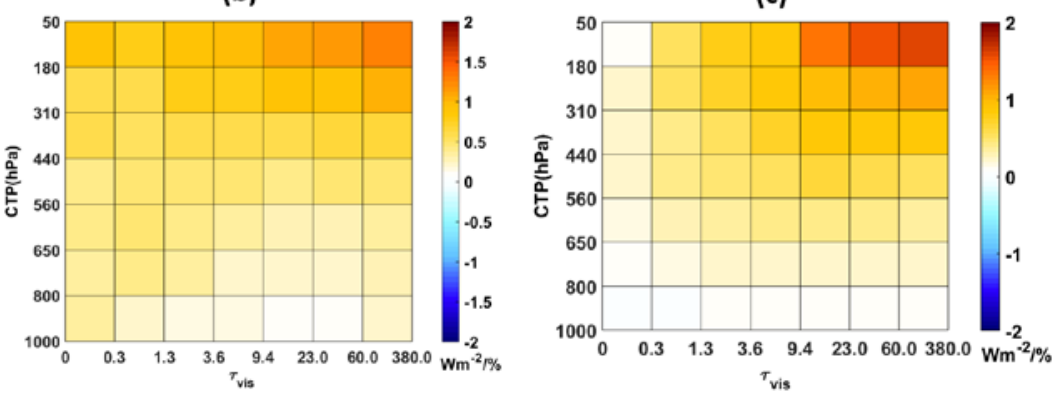

(e)

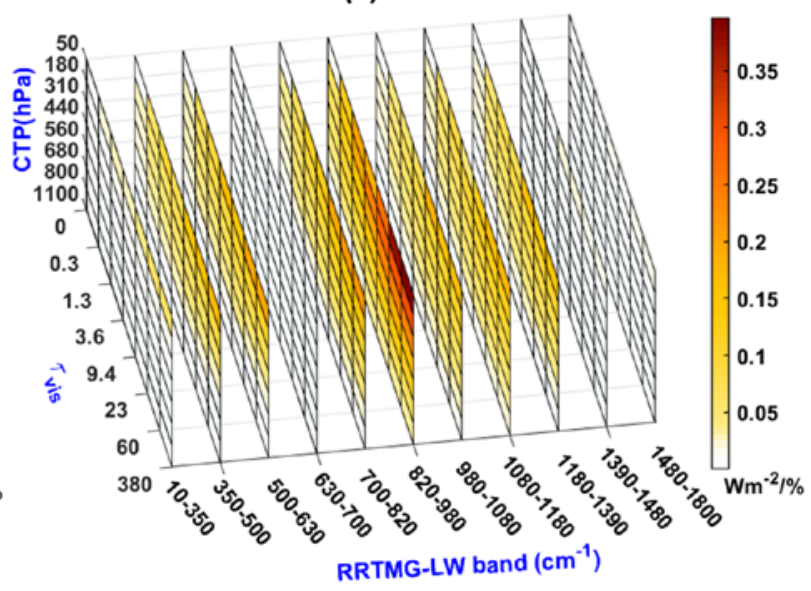

Figure 1. (a). The global-mean longwave (LW) cloud radiative kernel for January as computed in Zelinka et al. (2012). CTP refers to cloud top pressure and $\tau_{\text {vis }}$ refers to the visible cloud optical depth. (b) Same as (a) except based on Yue et al. (2016), which is derived from A-Train observations. (c) Same (b) except derived from the CESM simulation as described in Section 2. 
(d) The band-by-band decomposition of the cloud radiative kernel shown in (b). (e) The bandby-band decomposition of the cloud radiative kernel shown in (c).

This article is protected by copyright. All rights reserved. 
Adjust method
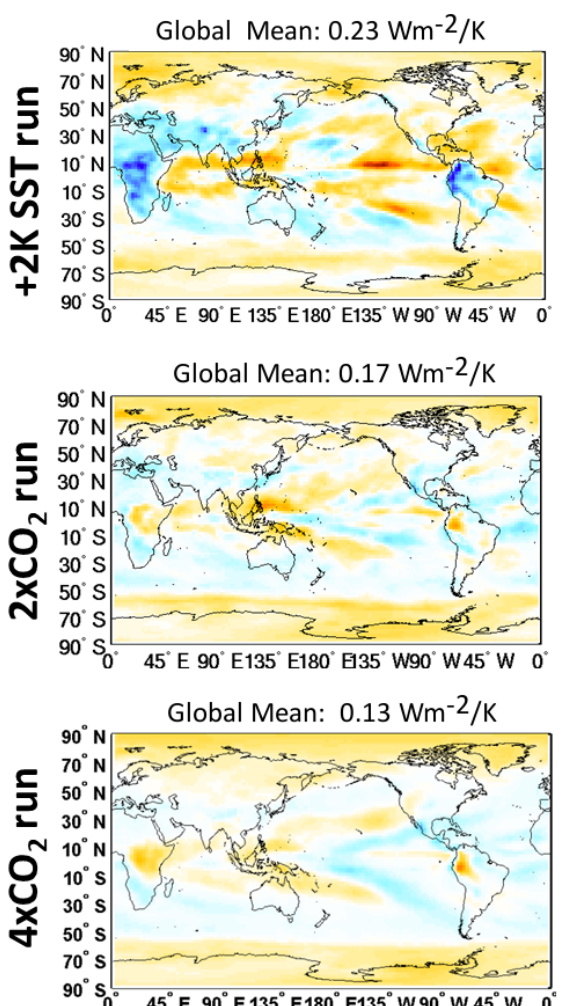

Kernel method

Global Mean: $0.20 \mathrm{Wm}^{-2} / \mathrm{K}$

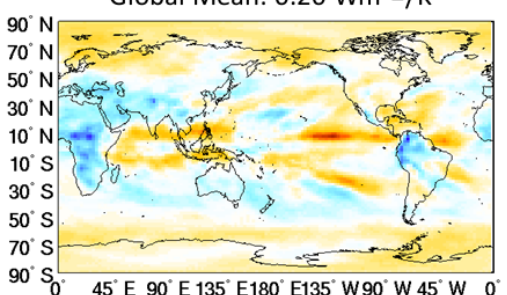

C
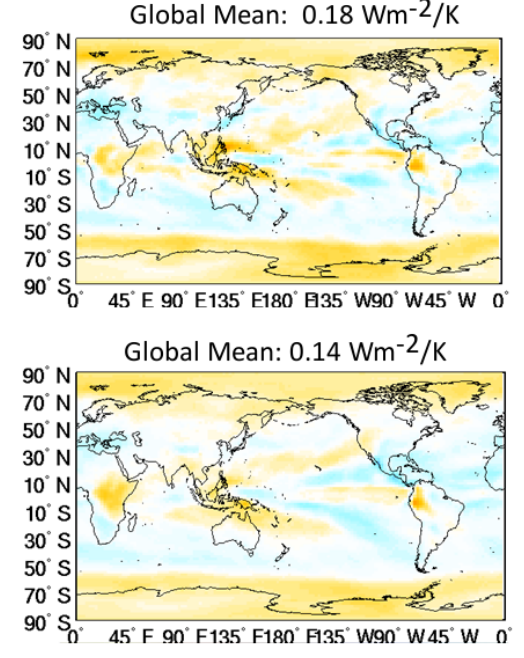

Kernel - Adjust

Global Mean:-0.03,RMSE:0.18Wm-2/K
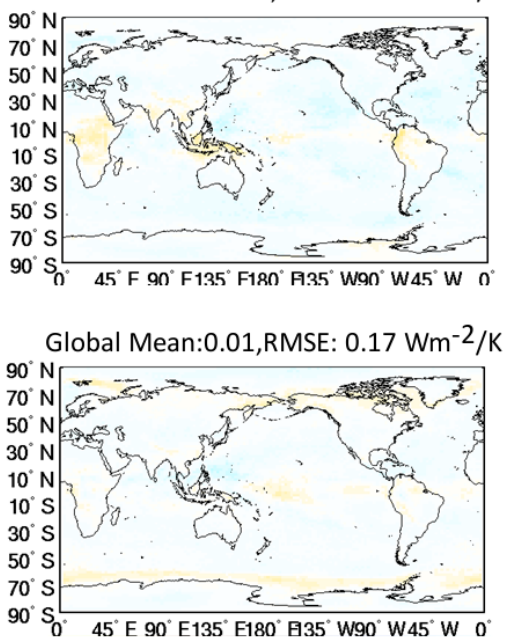

Global Mean:0.01,RMSE:0.15Wm-2/K

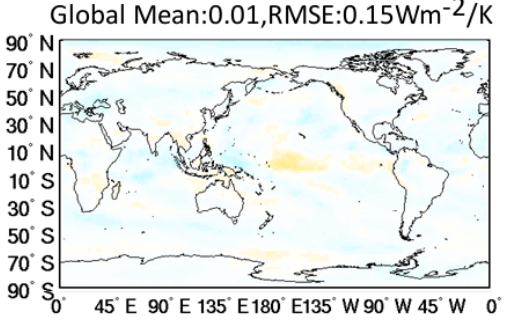

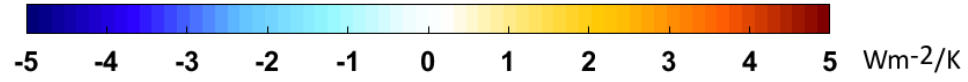

Figure 2. Left column: the LW cloud feedback as derived using the adjustment method. From top to bottom are results based on $+2 \mathrm{~K} \mathrm{SST}, 2 \times \mathrm{CO}_{2}$ run, and $4 \times \mathrm{CO}_{2}$ runs, respectively. Middle column: same as the left column but derived using the cloud radiative kernel method. The kernel is derived from 3-hourly CESM simulation output using the method described in Yue et al. (2016). Right column: the difference between the middle and left column. The global-mean value is labeled on top of each panel. 


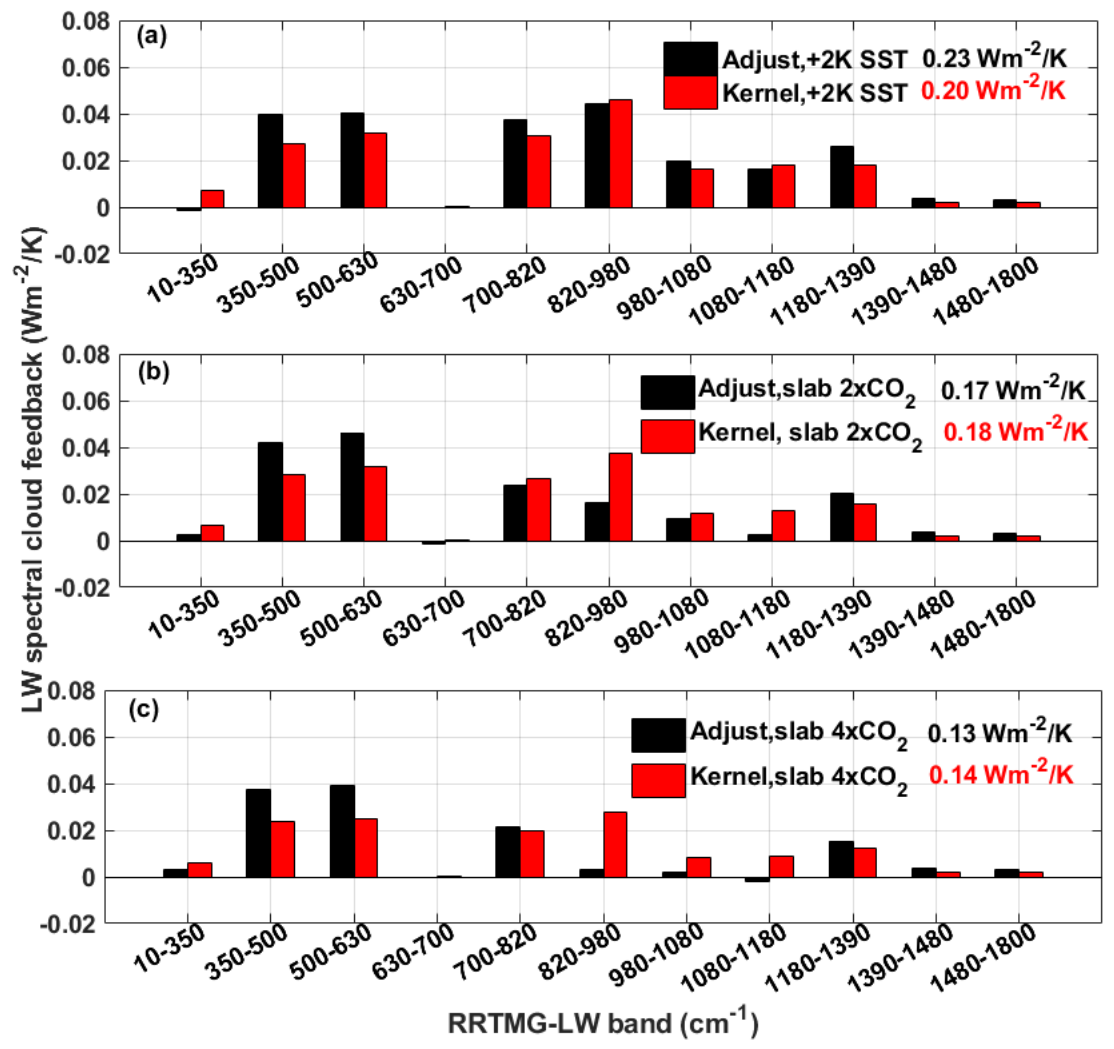

Figure 3. Decomposition of global LW cloud feedback onto the RRTMG_LW bands. Black and red bars are for the adjust and cloud radiative kernel methods, respectively. (a) for the $+2 \mathrm{~K}$ SST run. (b) for the $2 \times \mathrm{CO}_{2}$ run. (c) for the $4 \times \mathrm{CO}_{2}$ run. For each panel, the kernels built from the corresponding control run and the warming scenario run are averaged and used to derive the feedback. Broadband cloud feedbacks for three runs are labeled on three panels, respectively.

This article is protected by copyright. All rights reserved. 
(a)

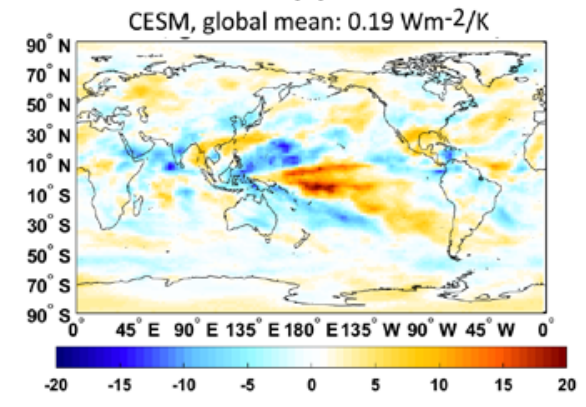

(c)

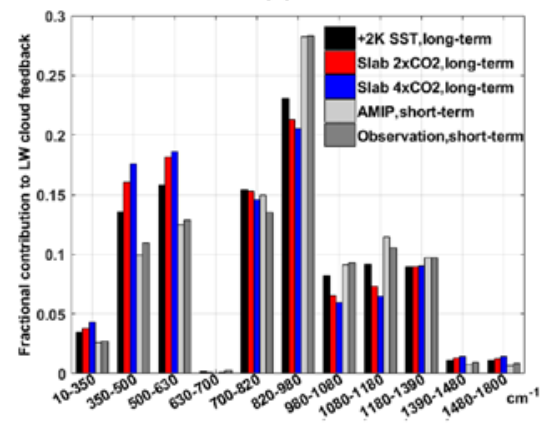

(b)

90. Observation, global mean: $0.19 \mathrm{Wm}-2 / \mathrm{K}$

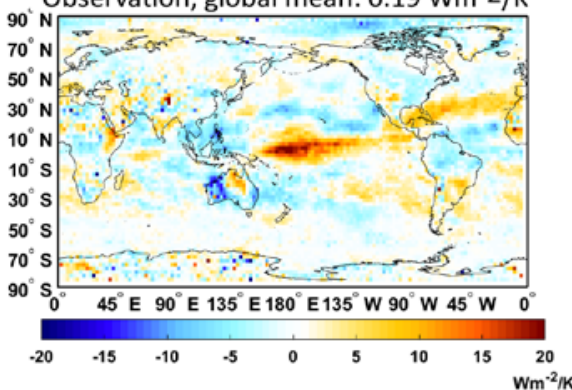

(d)

\begin{tabular}{|l|l|l|}
\hline & $\begin{array}{l}\text { Total fractional } \\
\text { contribution } \\
\text { from } 10-630 \\
\mathrm{~cm}^{-1} \text { (far-IR) }\end{array}$ & $\begin{array}{l}\text { Total fractional } \\
\text { contribution } \\
\text { from 820-1180 } \\
\mathrm{cm}^{-1} \text { (window) }\end{array}$ \\
\hline$+2 \mathrm{~K} \mathrm{SST}$ & 0.33 & 0.40 \\
\hline Slab $2 \times \mathrm{CO}_{2}$ & 0.38 & 0.35 \\
\hline Slab $4 \times \mathrm{CO}_{2}$ & 0.40 & 0.33 \\
\hline AMIP & 0.25 & 0.49 \\
\hline Observation & 0.26 & 0.48 \\
\hline
\end{tabular}

(e)

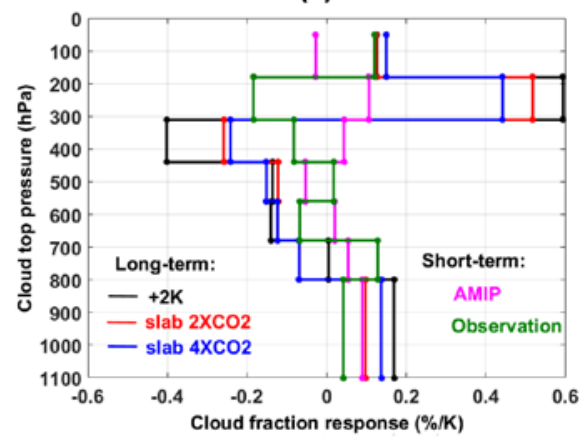

Figure 4. (a) The short-term cloud feedback derived from the CESM simulation forced by observed SST from 2003 to 2013. The CESM cloud radiative kernel is used. (b) Same as (a) but from the A-Train observations and the observation-based cloud radiative kernel in Yue et al. (2016) is used. (c) Fractional contribution of each RRTMG_LW band to the LW broadband cloud feedbacks. Different colors are for different simulations and observation as labeled on the plot. 
(d) The fractional contribution of the far-IR vs. mid-IR window region to LW cloud feedback for different simulations and observation. (e) Global-mean cloud fraction response to $1 \mathrm{~K}$ globalmean surface temperature increase, for all analyses shown in (c) and (d).

This article is protected by copyright. All rights reserved. 
(a)
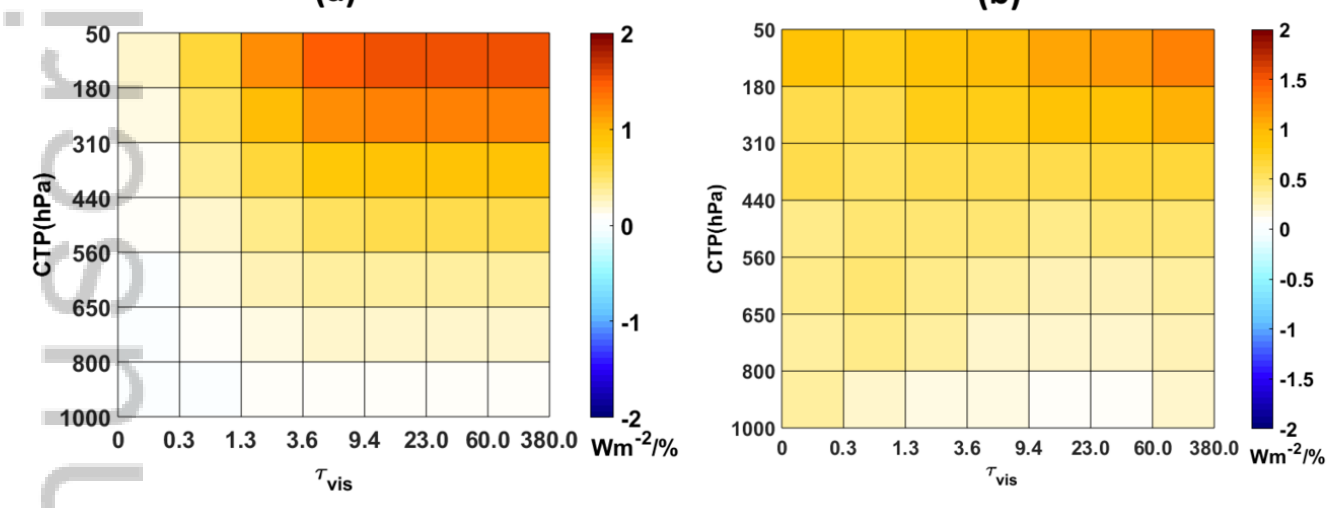

(d)
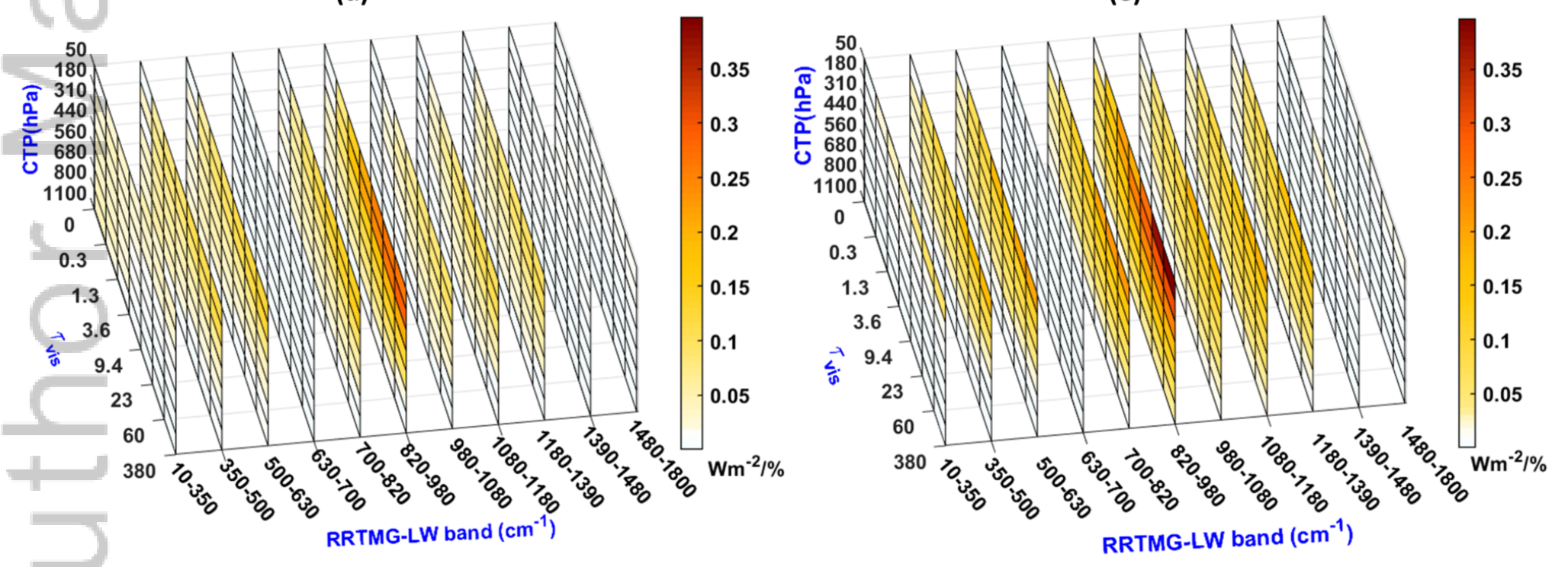

(c)

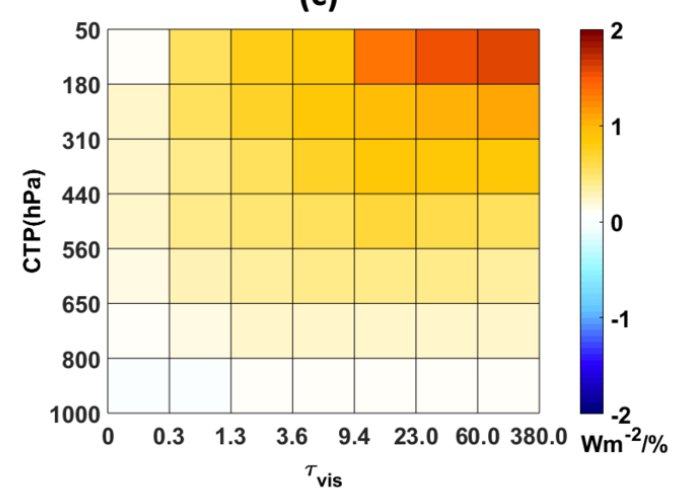

(e) RRTMG-LW band $\left(\mathrm{cm}^{-1}\right)$ 


\section{Adjust method}
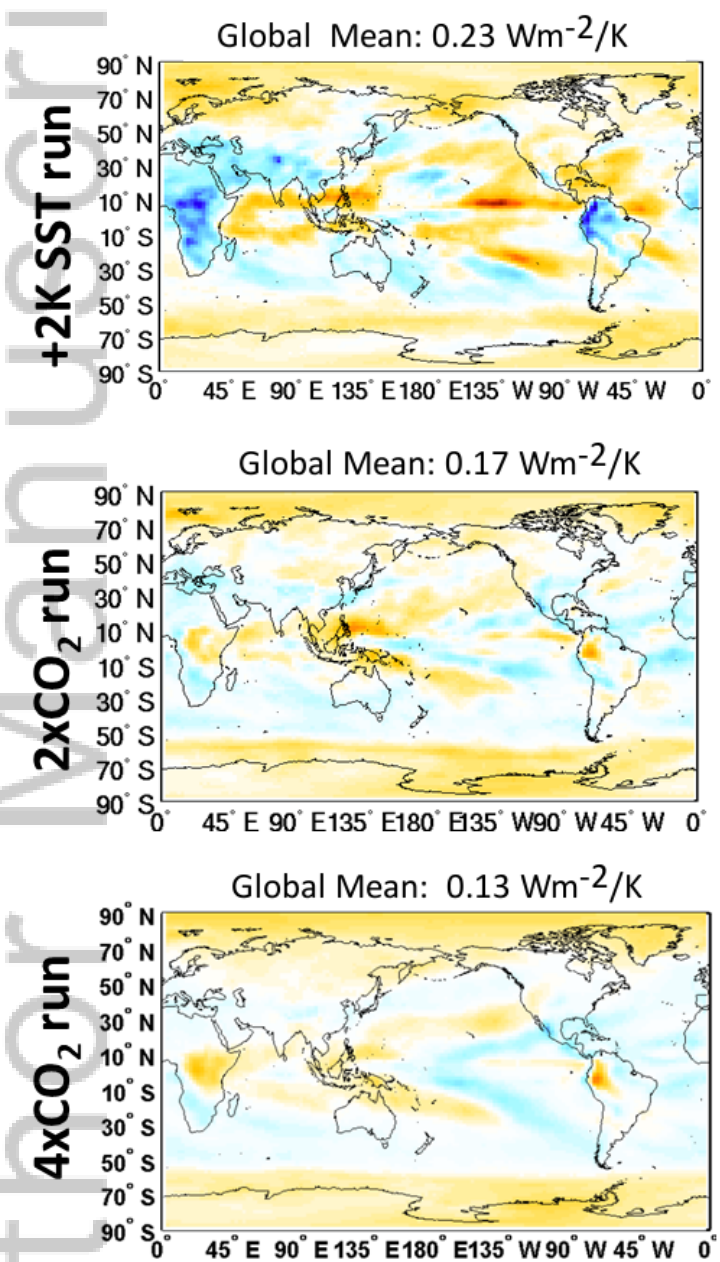

Kernel method

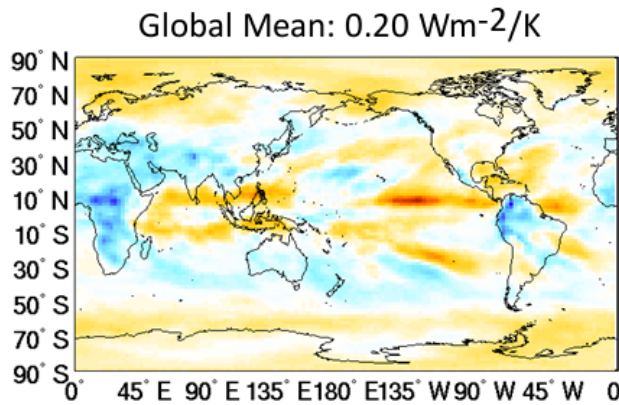

$90^{\circ} 45^{\circ} \mathrm{E} 90^{\circ} \mathrm{E} 135^{\circ} \mathrm{E} 180^{\circ} \mathrm{E} 135^{\circ} \mathrm{W} 90^{\circ} \mathrm{W} 45^{\circ} \mathrm{W}$
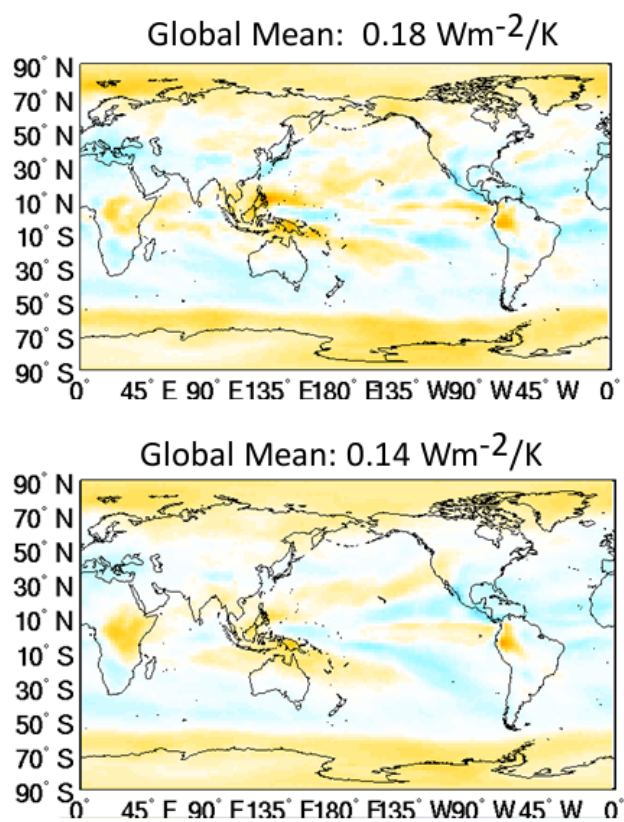

Kernel - Adjust

Global Mean:-0.03,RMSE:0.18Wm-2/K

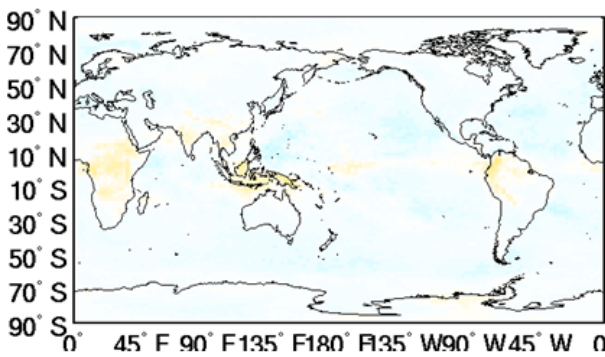

Global Mean:0.01,RMSE: $0.17 \mathrm{Wm}^{-2} / \mathrm{K}$

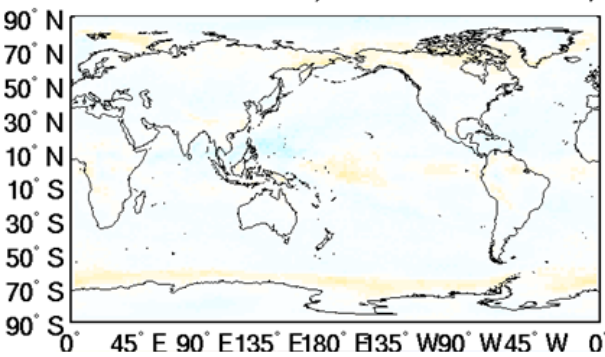

Global Mean:0.01,RMSE:0.15Wm-2/K

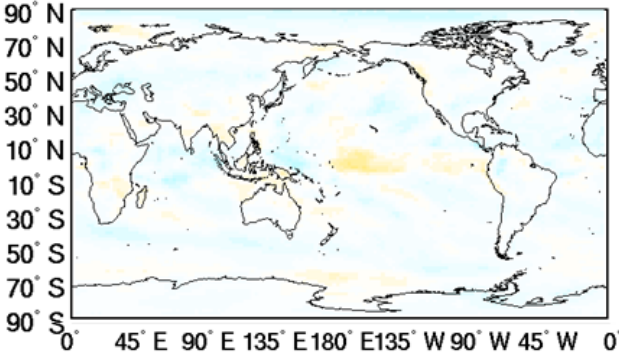

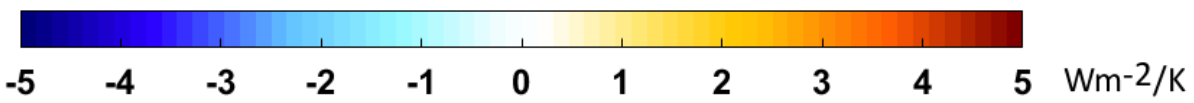

2019GL083466-f02-z-.tif 

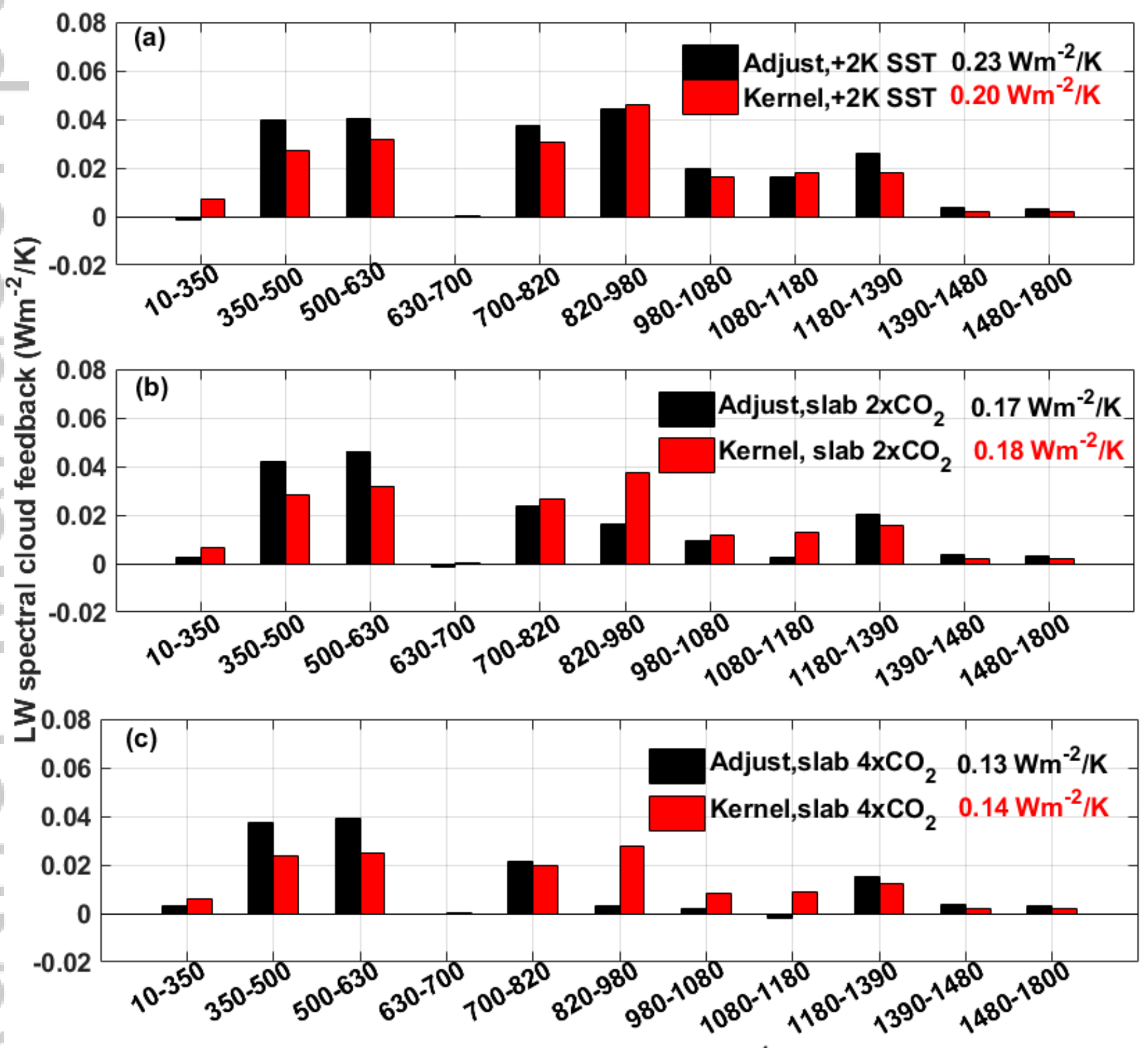

RRTMG-LW band $\left(\mathrm{cm}^{-1}\right)$

2019GL083466-f03-z-.tif 
(a)

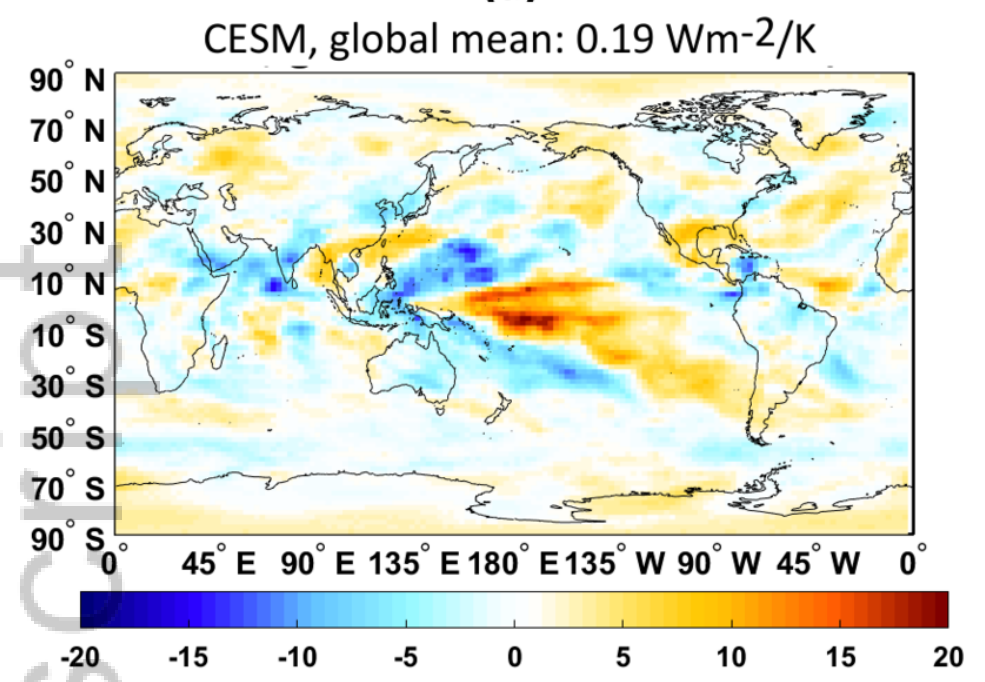

(c)

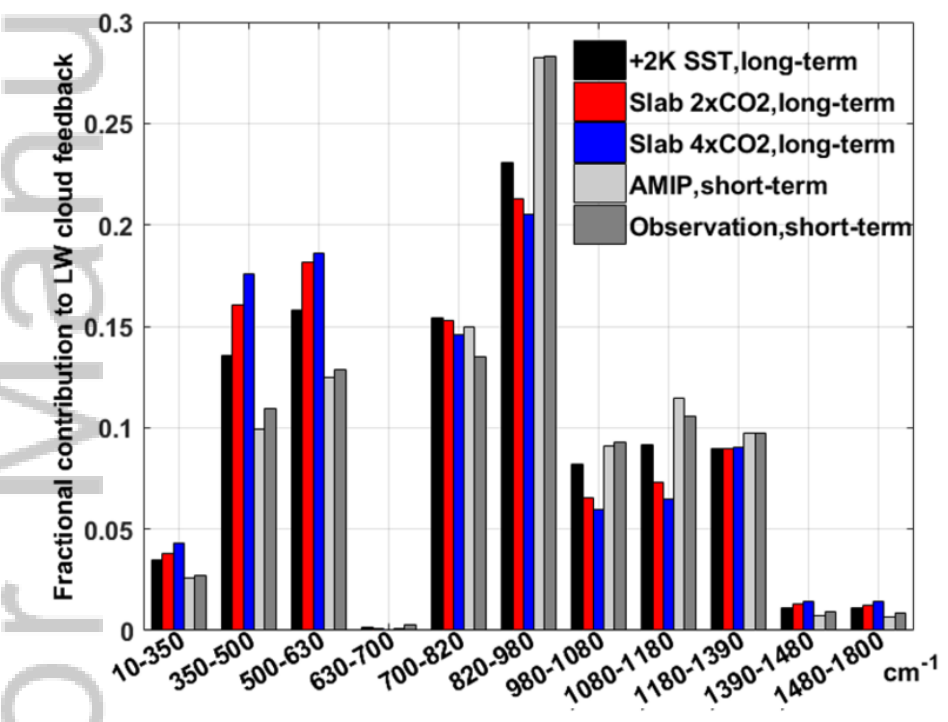

(b)

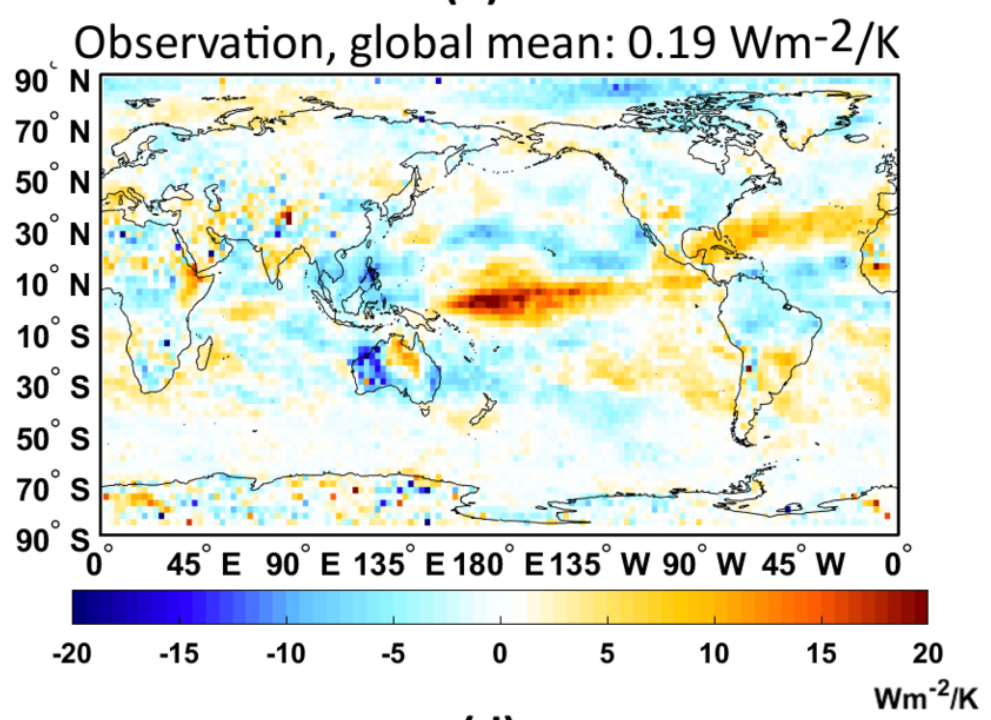

(d)

\begin{tabular}{|l|l|l|}
\hline & $\begin{array}{l}\text { Total fractional } \\
\text { contribution } \\
\text { from 10-630 } \\
\mathrm{cm}^{-1} \text { (far-IR) }\end{array}$ & $\begin{array}{l}\text { Total fractional } \\
\text { contribution } \\
\text { from } 820-1180 \\
\mathrm{~cm}^{-1} \text { (window) }\end{array}$ \\
\hline$+2 \mathrm{~K} \mathrm{SST}$ & 0.33 & 0.40 \\
\hline Slab $2 \times \mathrm{CO}_{2}$ & 0.38 & 0.35 \\
\hline Slab $4 \times \mathrm{CO}_{2}$ & 0.40 & 0.33 \\
\hline AMIP & 0.25 & 0.49 \\
\hline Observation & 0.26 & 0.48 \\
\hline
\end{tabular}

(e)

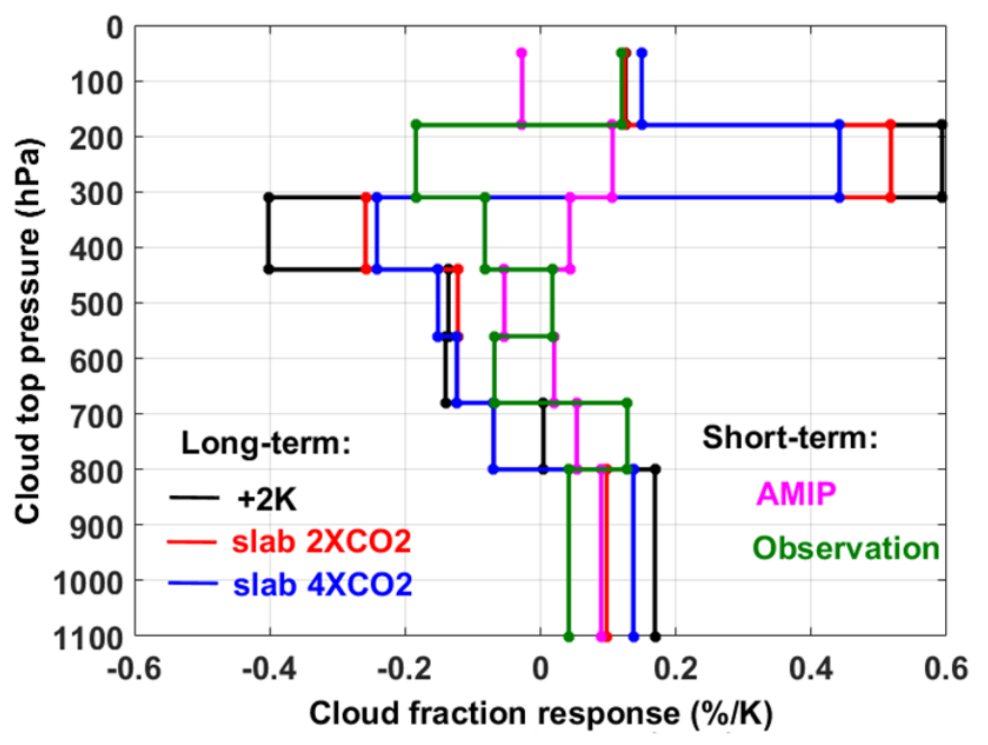

2019GL083466-f04-z-.tif 